\title{
Análise técnica da reciclagem de resíduos de construção em canteiro de obras
}

\author{
Technical analysis of the recycling of construction waste \\ in construction site
}

\begin{abstract}
Davi Valente Santos Antonio Eduardo Bezerra Cabral

\section{Resumo}

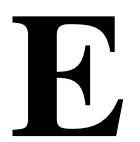

ste trabalho tem como objetivo avaliar tecnicamente a reciclagem de resíduos de construção civil provenientes de concreto e argamassa gerados em canteiro de obras de construtora de grande porte. Foram analisados traços de contrapiso e de emboço interno e externo, considerando substituição de areia natural por agregado reciclado nos percentuais de $25 \%$ e $50 \%$. Foram avaliadas propriedades no estado fresco (consistência, teor de ar incorporado, densidade de massa), no estado endurecido (densidade de massa aparente, módulo de elasticidade dinâmico, resistência à tração na flexão, resistência à compressão) e na argamassa de revestimento (aderência, fissuras e permeabilidade à água). Verificou-se que o teor de material pulverulento dos agregados reciclados foi menor do que $10 \%$, não havendo potencial impacto na fissuração. Observou-se também elevação do teor de ar incorporado com elevação do teor de substituição do agregado natural pelo reciclado nos traços de contrapiso e de emboço externo. Já para o emboço interno o comportamento foi o oposto. Em relação à aderência à tração, não houve impacto com relação ao teor de substituição. Para resistência à compressão e à tração na flexão, houve variações significativas, porém todas as argamassas permanecem no mesmo extrato de classificação segundo a NBR 13281. No que compete às fissuras, foram reduzidas com a substituição de areia natural por agregado reciclado. Em se tratando de permeabilidade à água, os resultados encontrados foram considerados baixos para todos os tipos de argamassas.
\end{abstract}

Palavras-chave: Resíduo de construção civil. Reciclagem. Argamassa.

\section{Abstract}

This work aims to technically evaluate the recycling of construction waste from concrete and mortar, generated on a construction site of a large construction company. Subfloor, internal and external coating mortars were analyzed, considering replacement of natural sand by recycled aggregate in the percentages of $25 \%$ and $50 \%$. Properties were evaluated in the fresh state (consistency, incorporated air content, mass density), in the hardened state (hardened density, modulus of elasticity, flexural strength, compressive strength) and in the coating mortar (adhesive strength, cracks and water permeability). It was found that the fine content of the recycled aggregates was less than 10\%, with no potential impact on cracking. It was also observed an increase in the content of

${ }^{1}$ Davi Valente Santos ${ }^{1}$ Faculdade Ari de Sá Fortaleza -CE - Brasil

\section{${ }^{2}$ Antonio Eduardo Bezerra}

Cabral

${ }^{2}$ Universidade Federal do Ceará Fortaleza -CE - Brasil

Recebido em 01/09/19 Aceito em 17/03/20 incorporated air with an increase in the content of substitution of natural aggregate for recycled in the mortars of subfloor and external coating mortars, however for the internal coating mortars the behavior was the opposite. Regarding adhesive strength, there was no impact on the replacement content. For compressive and flexural strength, there were significant variations, but all mortars remain in the same classification extract, according to NBR 13281. As far as cracks are concerned, these were reduced by replacing natural sand with recycled aggregate. In terms of water permeability, the results found were considered low for all types of mortars.

Keywords: Construction waste. Recycling. Mortar. 


\section{Introdução}

Em países em desenvolvimento, como o Brasil, o setor da construção civil possui papel importante no processo de crescimento e redução do desemprego em virtude de sua célere capacidade de geração de vagas diretas e indiretas no mercado de trabalho. Assim, percebe-se o papel estratégico do setor no combate ao déficit habitacional e ao desemprego. Todavia, a construção civil é uma atividade econômica com efeitos nocivos ao meio ambiente por contribuir para o esgotamento dos recursos naturais, consumir energia, poluir o ar, o solo e a água, e produzir resíduos (NETO, 2005).

$\mathrm{O}$ crescimento da indústria da construção tem elevado consideravelmente o consumo de matérias-primas naturais e a produção de resíduos de construção civil (RCC), intensificando problemas derivados de procedimentos inadequados, como a disposição sem controle desses resíduos nas grandes cidades (OSSA; GARCÍA; BOTERO, 2016). Destaca-se que as construtoras são responsáveis por 50\% dos resíduos de construção civil gerados no Brasil, enquanto o restante é gerado informalmente (JOHN et al., 2004). Além disso, por serem materiais volumosos e de elevada massa específica, a disposição de RCC gera impacto ambiental negativo.

É pacífico no meio científico que a geração de resíduos de construção é considerada atividade insustentável, que causa progressiva deterioração do meio ambiente (MEJÍA et al., 2015). Ela representa 50\% do total de resíduos sólidos urbanos gerados em âmbito global (RODRIGUES et al., 2013). Por exemplo, no Brasil se produz mais de $70 \mathrm{Mt} /$ ano de RCC (CONTRERAS et al., 2016). Além disso, a atividade de construção consome $40 \%$ dos recursos naturais não renováveis (YUAN et al., 2011). Destaca-se ainda que cerca de 90\% da massa total de RCC gerada no Brasil e na Europa é composta de concretos, argamassas, solo e gesso (ULSEN et al., 2010). Em Fortaleza, no estado do Ceará, o RCC é composto de 93,4\% da classe A, conforme classificação da Resolução no 307 do Conama (LIMA; CABRAL, 2013).

Mais de $75 \%$ dos resíduos gerados pela indústria da construção civil têm potencial de valoração, reciclagem ou reúso (YEHEYIS et al., 2013). Os RCC apresentam, portanto, elevado potencial de reciclagem e baixa periculosidade, consequentemente não os reaproveitar significa perder importante fonte de materiais alternativos. O uso desses resíduos como agregados alternativos pode contribuir para reduzir a retirada de matéria-prima de fontes nãorenováveis e minorar gastos e impactos associados com a extração de recursos naturais (CARNEIRO et al., 2001).

A incorporação de agregados graúdos provenientes de RCC na confecção de concreto tem sido amplamente estudada por vários pesquisadores (ZORDAN, 1997; OLIVEIRA, 2002; VIEIRA; DAL MOLIN, 2004; CABRAL, 2007; CORREIA; BRITO; PEREIRA, 2007; ETXEBERRIA et al., 2007; RICHARDSON; COVENTRY; BACON, 2011; KOU; POON; WAN, 2012; SHEEN et al., 2013; SILVA; BRITO; DHIR, 2014; BRAVO et al., 2015a, 2015b; MEDINA et al., 2015). Porém, não há consenso na utilização de tais agregados reciclados como agregados miúdos, uma vez que estes apresentam características potencialmente prejudiciais ao concreto e à argamassa devido asua elevada absorção de água (BRAVO et al., 2015b). Pesquisas realizadas por Khatib (2005) eEvangelista e Brito (2007, 2014) indicam a viabilidade do uso de RCC como agregado miúdo, desde que não leve a perdas significativas das propriedades do concreto ou das argamassas, seja em termos mecânicos, seja em durabilidade.

Estudos de Miranda e Selmo (2006), Braga, Brito e Veiga (2012), Fan et al. (2015), Silva, Brito e Dhir (2016) e Martínez et al. (2018) abordam a utilização de agregados reciclados em argamassas. Todos esses estudos apontam para a viabilidade de uso de agregados reciclados, mesmo contendo significativo teor de finos, para argamassas.

Silva, Brito e Dhir (2016) realizaram diversas análises e, entre as conclusões, destacam que há uma profunda influência do aumento da absorção por parte de agregados reciclados na consistência da argamassa em função do aumento de área superficial, da irregularidade e da rugosidade do agregado reciclado, aumentando a fricção entre as partículas. Além disso, para argamassas com relação água-cimento (a/c) relativamente baixa, as propriedades mecânicas de resistência à compressão e à tração na flexão tendem a decrescer com o aumento do teor de substituição do agregado natural pelo reciclado. Para o módulo de elasticidade, o comportamento é análogo, melhorando, portanto, seu comportamento quanto à absorção de deformações provenientes do substrato. A utilização de agregados reciclados apresentou também melhora na propriedade de aderência das argamassas estudadas. Por fim, o estudo concluiuque a utilização da fração mais fina do agregado reciclado é viável para fins de construção.

Martínez et al. (2018) avaliaram que o teor de finos possui fundamental importância na definição do agregado reciclado a se utilizar para fins de construção civil. Os pesquisadores pontuaram que a relação a/c

364 Santos, D. V.; Cabral, A. E. B. 
pode ser utilizada como parâmetro de controle das propriedades mecânicas das argamassas e que o teor de finos é o melhor parâmetro de controle do potencial de retração das argamassas em relação à a/c.

Portanto, inserido nesse contexto, com este trabalho busca-se estabelecer uma análise técnica da reciclagem de resíduos produzidos e beneficiados na obra em construtora localizada em Fortaleza, CE.

\section{Materiais e métodos}

\section{Processo de reciclagem e definições de parâmetros}

O ambiente de pesquisa foi constituído por edifício residencial multifamiliar de uma construtora de grande porte, construído em terreno de $3.577,12 \mathrm{~m}^{2}$, possuindo aproximadamente $21.627,20 \mathrm{~m}^{2}$ de área construída. Essa obra é constituída de vinte e dois pavimentos-tipo, com seis apartamentos por andar, com áreas privativas de $117,19 \mathrm{~m}^{2}$ e $85,07 \mathrm{~m}^{2}$, além de um pavimento-cobertura, um pilotis e dois subsolos. A estrutura foi do tipo reticulada de concreto armado e protendido, e a vedação externa foi realizada com bloco cerâmico de 14x19x19 cm. Processaram-se nessa obra todas as avaliações técnicas, considerando aspectos mecânicos, físicos, químicos e processuais, desde a confecção das argamassas com agregados reciclados, sua aplicação e verificação de suas propriedades no estado fresco e endurecido.

O processo de reciclagem foi realizado mediante britagem do resíduo proveniente de concreto e argamassa, no próprio canteiro, como britador Queixada Q200 RI, mostrado na Figura 1. Dados técnicos encontram-se na Tabela 1.

Os traços utilizados foram os mesmos adotados pela construtora para contrapiso, emboço interno e externo, e são respectivamente 1:2,5 (cimento, areia grossa peneirada \#4,75 mm), 1:1,5:2 (cimento, arisco, areia grossa peneirada \#4,75 mm) e 1:1:3 (cimento, cal, areia grossa peneirada \#4,75 mm), todos em volume. Considerou-se, com base nos trabalhos de Martinez et al. (2018), Lovato e Menegatti (2015), Ledesman et al. (2014), Martinez et al. (2013), Jiménez et al. (2013) e Oliveira e Cabral (2011), que o teor ótimo de substituição de areia natural por agregado reciclado para produção de argamassa fica em torno de $40 \%$ a $50 \%$. Portanto, foram confeccionadas argamassas com traços de referência e com teores de substituição de $25 \%$ e $50 \%$ na análise técnica.

Para a análise técnica, foram realizados ensaios com agregados, argamassa no estado fresco e no estado endurecido, e argamassa de revestimento, conforme a Tabela 2. Todos seguiram as normas destacadas na tabela supracitada. A Tabela 3 mostra os ensaios de argamassa no estado endurecido, considerando a quantidade de corpos de prova utilizados.

Figura 1 - Britador Queixada Q200 RI

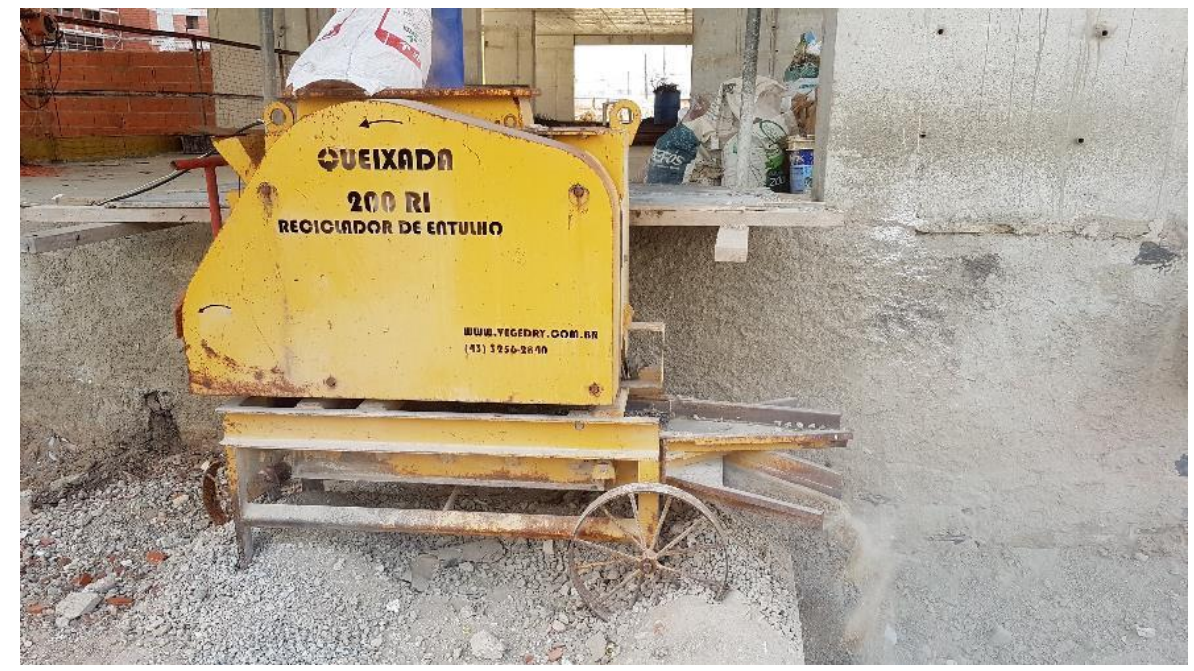


Tabela 1 - Dados técnicos do Britador Queixada Q200 RI

\begin{tabular}{l|c}
\hline \multicolumn{2}{c}{ BRITADOR QUEIXADA Q200 RI } \\
\hline Produção média (fino + brita) & $1,1 \mathrm{~m}^{3} / \mathrm{h}$ \\
Abertura das mandíbulas ajustável & $6-16 \mathrm{~mm}$ \\
Abertura de entrada das mandíbulas & $200 \times 170 \mathrm{~mm}$ \\
\hline
\end{tabular}

Fonte: REHNI - Máquinas e Equipamentos (2017).

Tabela 2 - Ensaios para análise técnica

\begin{tabular}{|c|c|c|}
\hline Etapa & Ensaio & Fonte \\
\hline \multirow{8}{*}{$\begin{array}{l}\text { Caracterização } \\
\text { dos materiais }\end{array}$} & Composição granulométrica & \multirow{3}{*}{ NBR NM 248 (ABNT, 2003a) } \\
\hline & Dimensão máxima característica & \\
\hline & Módulo de finura & \\
\hline & Massa específica $\left(\mathrm{g} / \mathrm{cm}^{3}\right)$ & $\begin{array}{l}\text { NBR } 16605 \text { (ABNT, 2017) e NBR } \\
\text { NM } 52 \text { (ABNT, 2009a) }\end{array}$ \\
\hline & Massa unitária no estado solto $\left(\mathrm{g} / \mathrm{cm}^{3}\right)$ & NBR NM 45 (ABNT, 2006) \\
\hline & Absorção & NBR NM 30 (ABNT, 2001) \\
\hline & Teor de material pulverulento & NBR NM 46 (ABNT, 2003b) \\
\hline & Forma e angularidade dos agregados & TP 81 (AMERICAN..., 2012) \\
\hline \multirow{3}{*}{$\begin{array}{l}\text { Argamassa no } \\
\text { estado fresco }\end{array}$} & Índice de consistência & NBR 13276 (ABNT, 2016) \\
\hline & Teor de ar incorporado & \multirow{2}{*}{ NBR 13278 (ABNT, 2005a) } \\
\hline & Determinação da densidade de massa & \\
\hline \multirow{4}{*}{$\begin{array}{l}\text { Argamassa no } \\
\text { estado endurecido }\end{array}$} & $\begin{array}{l}\text { Densidade de massa aparente no estado } \\
\text { endurecido }\end{array}$ & NBR 13280 (ABNT, 2005b) \\
\hline & Módulo de elasticidade dinâmico & NBR 15630 (ABNT, 2008) \\
\hline & Resistência à tração na flexão & \multirow{2}{*}{ NBR 13279 (ABNT, 2005c) } \\
\hline & Resistência à compressão & \\
\hline \multirow{3}{*}{$\begin{array}{l}\text { Argamassa de } \\
\text { revestimento }\end{array}$} & Fissura & - \\
\hline & Teste do cachimbo & (CENTRE..., 1982; RILEM, 1982) \\
\hline & Resistência de aderência à tração & NBR 15258 (ABNT, 2005d) \\
\hline
\end{tabular}

Tabela 3 - Ensaios de argamassas no estado endurecido

\begin{tabular}{l|c|c|c}
\hline \multicolumn{1}{c|}{ Ensaio } & Idade (dias) & $\begin{array}{c}\text { Quantidade de } \\
\text { CP/traço }\end{array}$ & Norma \\
\hline $\begin{array}{l}\text { Densidade de massa aparente } \\
\text { no estado endurecido }\end{array}$ & 28 & 3 & NBR 13280 (ABNT, 2005b) \\
\hline $\begin{array}{l}\text { Módulo de elasticidade } \\
\text { dinâmico }\end{array}$ & 28 & 3 & NBR 15630 (ABNT, 2008) \\
\hline \multirow{2yyn}{*}{ Resistência à tração na flexão } & 7 & 3 & \multirow{2}{*}{ NBR 13279 (ABNT, 2005c) } \\
\cline { 1 - 3 } Resistência à compressão & 28 & 3 & \\
\cline { 1 - 3 } & 28 & 6 & 6 \\
\hline
\end{tabular}

Destaca-se que os intervalos de consistências adotados foram definidos com base em ensaio com mesa de consistência realizado in loco, com as argamassas produzidas na obra. Para as argamassas de contrapiso,

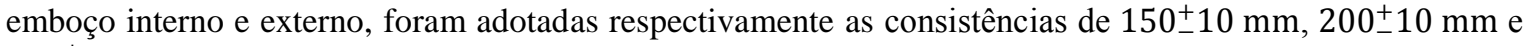
$270_{-}^{+} 10 \mathrm{~mm}$.

A técnica de processamento digital de imagem (PDI) foi utilizada para a análise de forma e angularidade da areia natural e dos agregados reciclados, conforme a TP 81 (AMERICAN..., 2012). O AIMS (Aggregate Image Measurement System), equipamento utilizado para a realização dessa técnica, foi desenvolvido para analisar parâmetros de forma de partículas de agregados (forma propriamente dita, angularidade e textura superficial). Ele utiliza um sistema simples de aquisição de imagens. Através de uma câmera microscópica e de dois tipos de iluminação, é capaz de capturar as imagens dos agregados em diferentes resoluções, e, a partir destas, as propriedades de forma são obtidas. A principal vantagem com relação ao uso desse 
equipamento é a possibilidade de obtenção de resultados de distribuições de propriedades, e não apenas médias de valores, como fornecem ensaios tradicionais. O equipamento está ilustrado na Figura 2.

Al Rousan (2004) realizou diversos ensaios em diferentes tipos de agregados, com composições mineralógicas e propriedades de forma, de angularidade e de textura distintas, com o objetivo de desenvolver uma metodologia de classificação dos agregados de acordo com o resultado de cada uma de suas propriedades analisadas. Com isso, determinaram-se os limites de classificação para os parâmetros obtidos através do AIMS. A Tabela 4 destaca somente os índices de classificação para agregado miúdo, objeto do presente estudo, e as Equações 1 e 2 mostram as equações da forma $2 \mathrm{D}$ e esfericidade, propriedades estudadas para agregados miúdo no AIMS.

Forma $2 D=\sum_{\theta=0}^{\theta=360-\Delta \theta}\left[\frac{R_{\theta}+\Delta \theta-R_{\theta}}{R_{\theta}}\right]$

Onde:

$R_{\theta}=$ raio da partícula no ângulo $0^{\circ}$ de referência; e

$\Delta \theta=$ diferença de incremento no ângulo.

Esfericidade $=\sqrt[3]{\frac{d_{S} d_{I}}{d_{L}^{2}}}$

Onde:

$d_{s}=$ menor dimensão do agregado;

$d_{I}=$ dimensão intermediária do agregado; e

$d_{L}=$ maior dimensão do agregado.

A fissuração foi avaliada em cada painel sob a luz natural, identificando-se a quantidade, a espessura e o comprimento das fissuras com o auxílio de fissurômetro e barbante para verificação do comprimento de fissura. As medições foram realizadas aos 28 dias nos painéis de $50 \times 50 \mathrm{~cm}$ para os traços de contrapiso, emboço interno e externo.

No que compete ao ensaio de permeabilidade à água, foi realizado pelo método do cachimbo, conforme ilustrado na Figura 3. Preencheu-se o cachimbo de vidro com água e observou-se a variação de volume por 15 min. Realizaram-se duas determinações por painel, considerando-se o valor médio como a permeabilidade à água da argamassa observada.

A aderência da argamassa ao substrato foi avaliada pelo ensaio de resistência de aderência à tração, aos 28 dias de idade, em painéis $50 \times 50 \mathrm{~cm}$, para os traços de contrapiso, emboço interno e emboço externo. Os painéis de contrapiso tinham como substrato laje de concreto armado. Já os painéis dos emboços foram confeccionados sobre alvenaria chapiscada de bloco cerâmico de 14x19x19 cm. Para a realização desse ensaio, foi utilizado o equipamento hidráulico modelo Dinateste e pastilhas de ferro com seção circular de $50 \mathrm{~mm}$ de diâmetro. A Figura 4 ilustra os painéis de 50x50 cm de emboço externo.

Figura 2 - AIMS: Visão geral (a) e parte interna do equipamento (b)

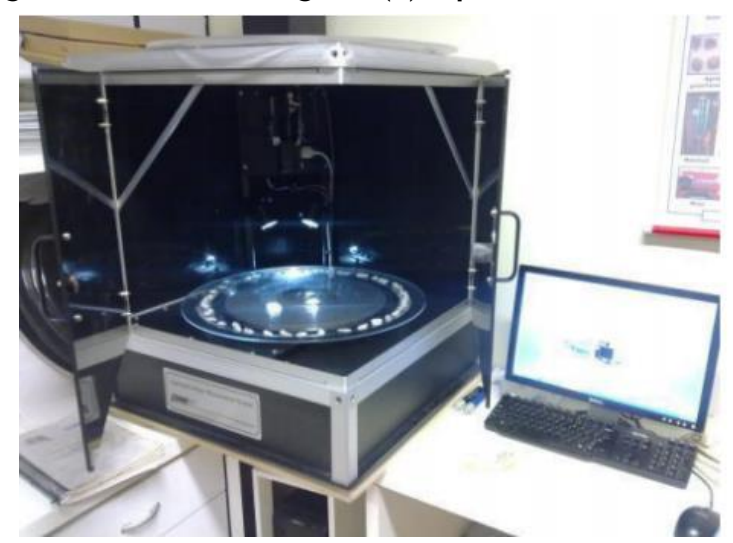

(a)

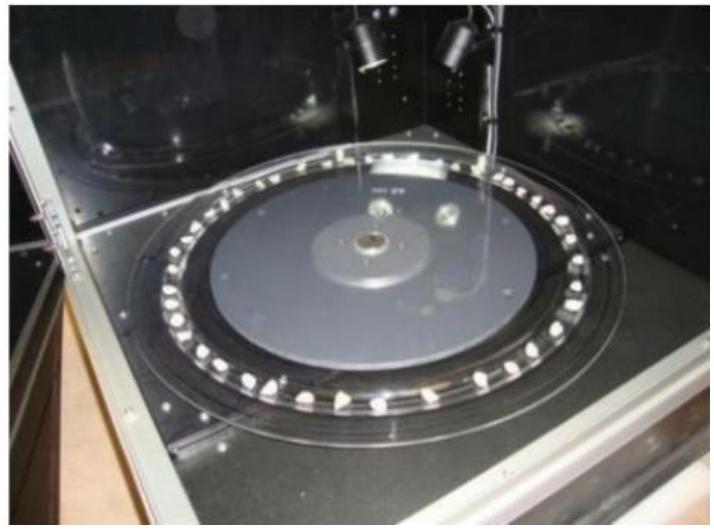

(b) 
Tabela 4 - Ensaios de argamassas no estado endurecido

\begin{tabular}{l|c|c|c|c}
\hline \multicolumn{1}{c|}{ Propriedade } & \multicolumn{4}{|c}{ Valores-limite/Classificação } \\
\hline \multirow{2}{*}{ Forma 2D } & $<6,5$ & $6,5-8,0$ & $8,0-10,5$ & $>10,5$ \\
\cline { 2 - 5 } & Circular & Semicircular & Semialongado & Alongado \\
\hline \multirow{2}{*}{ Angularidade } & $<2.100$ & $2.100-4.000$ & $4.000-5.400$ & $>5.400$ \\
\cline { 2 - 5 } & Arredondado & Subarredondado & Subangular & Angular \\
\hline
\end{tabular}

Figura 3 - Ensaio de permeabilidade à água

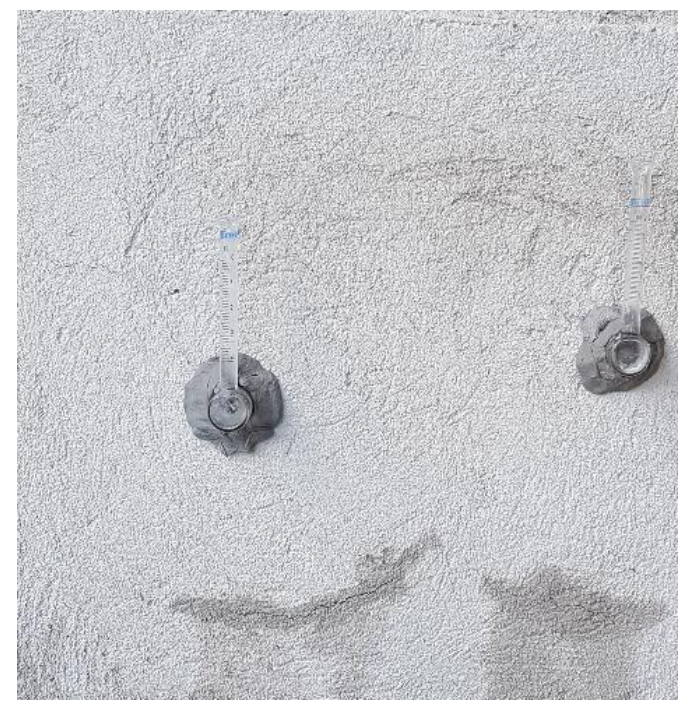

Figura 4 - Painéis de emboço externo

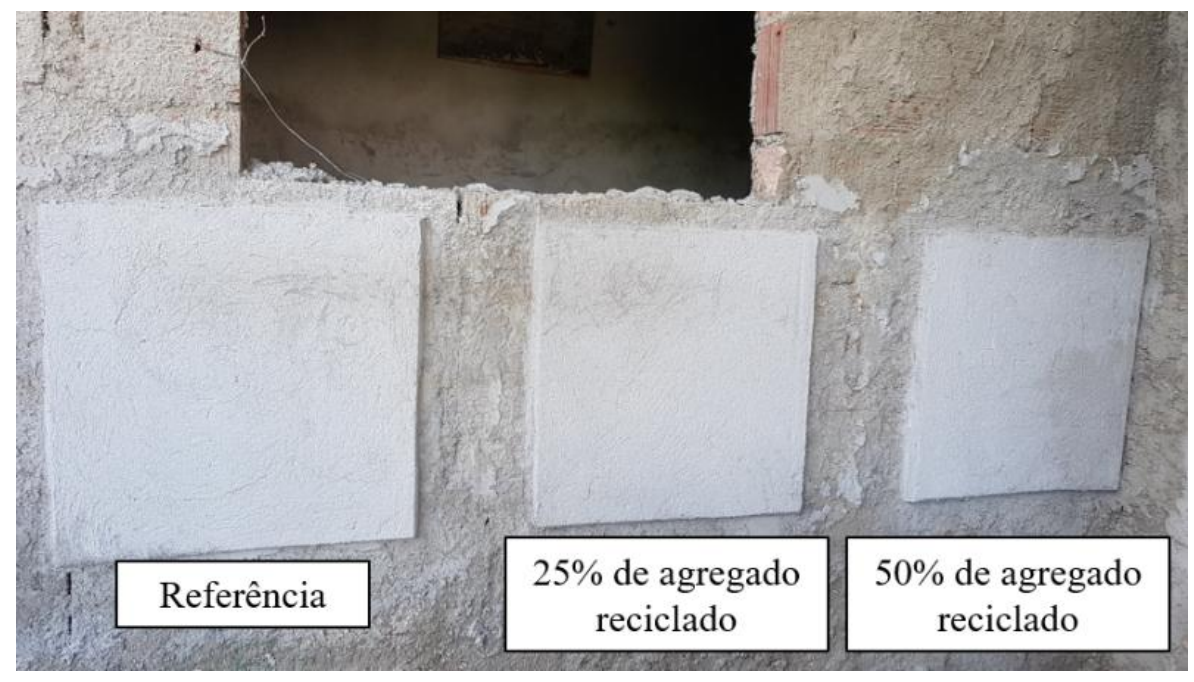

Os ensaios de caracterização dos blocos cerâmicos que serviram de substrato para as argamassas não foram realizados. Porém, destaca-se que todos os testes de aderência, permeabilidade e fissuração foram realizados na mesma obra, com o mesmo substrato, nas mesmas condições ambientais. Portanto, não há diferença de interação substrato-revestimento entre as argamassas utilizadas.

\section{Caracterização dos materiais}

\section{Aglomerantes}

Utilizou-se o cimento Portland POTY do tipo CP II-E-32, por ser o cimento adotado pela construtora estudada. A massa unitária do cimento foi de $1,40 \mathrm{~g} / \mathrm{cm}^{3}$.

368 Santos, D. V.; Cabral, A. E. B. 
As Tabelas 5 e 6 apresentam respectivamente as características químicas e físicas do cimento utilizado. Todos os dados foram fornecidos pelo fabricante.

A cal hidratada utilizada é a do tipo CH-I, da marca Extra, por esta ser a cal utilizada na empresa. Conforme o fabricante, essa cal hidratada atende aos requisitos exigidos pela NBR 7175 (ABNT, 2003b). Sua massa específica foi de $2,30 \mathrm{~g} / \mathrm{cm}^{3}$, e sua massa unitária foi de $0,62 \mathrm{~g} / \mathrm{cm}^{3}$.

\section{Agregados miúdos naturais e reciclados}

$\mathrm{Na}$ confecção das argamassas, foram utilizadas areia lavada de rio, arisco ${ }^{1}$ e agregados reciclados provenientes de resíduos de concreto e argamassa, portanto classe A, conforme a Resolução Conama $\mathrm{n}^{\circ} 307$. A Figura 5 ilustra os agregados naturais e os reciclados extraídos do britador Queixada Q200 RI. Ressalta-se que o agregado reciclado A3 foi descartado em virtude de sua granulometria e que o agregado reciclado AM é a mistura de A1 e A2.

A Figura 6 e a Tabela 7 apresentam respectivamente as curvas granulométricas e as dimensões percentuais principais da areia utilizada pela empresa e dos agregados reciclados gerados pela britagem de resíduos de concreto e argamassa misturados. É válido ressaltar que, em virtude de os resíduos de cerâmica vermelha serem mais delgados, acabavam, em sua maioria, não sendo britados corretamente, passando pelas mandíbulas do britador. Portanto, optou-se por trabalhar com resíduos de concreto e argamassa.

Observa-se que os agregados reciclados A1, A2 e AM estão, quase em sua totalidade, dentro da zona utilizável para concreto estabelecida pela NBR 7211 (ABNT, 2009b). Embora esses limites sejam para concreto, e não para argamassa, servem de parâmetro de análise, uma vez que não há normas brasileiras contemplando tais limites para a confecção de argamassa. Destaca-se ainda, conforme ilustrado na Tabela 5, que a areia possui granulometria mais próxima da do resíduo A1. Porém, adotou-se o agregado reciclado AM nas análises de substituição com o intuito de aproveitar o máximo do agregado reciclado gerado pelo processo e pelo fato de esse apresentar-se, em sua totalidade, dentro da zona utilizável.

Tabela 5 - Características químicas do cimento (valores médios)

\begin{tabular}{l|c|c}
\hline Composição química do clínquer & Teores & Limite da norma \\
\hline Óxido de magnésio - MgO & $3,30 \%$ & $6,50 \%$ \\
Trióxido de enxofre - $\mathbf{S O}_{3}$ & $3,27 \%$ & $4,00 \%$ \\
Resíduo insolúvel -RI & $1,96 \%$ & $16,0 \%$ \\
Perda ao fogo -PF & $4,94 \%$ & $6,50 \%$ \\
\hline
\end{tabular}

Fonte: Votorantim Cimentos (2017).

Tabela 6 - Características físicas e mecânicas do cimento (valores médios)

\begin{tabular}{|c|c|c|c|}
\hline \multicolumn{2}{|l|}{ Ensaio } & Resultado & Limite da norma \\
\hline \multicolumn{2}{|l|}{ Massa específica } & $3,05 \mathrm{~g} / \mathrm{cm}^{3}$ & $\geq 2,8 \mathrm{e} \leq 3,2 \mathrm{~g} / \mathrm{cm}^{3}$ \\
\hline \multicolumn{2}{|l|}{ Área específica (Blaine) } & $3.840 \mathrm{~cm}^{2} / \mathrm{g}$ & $\geq 2.600 \mathrm{~cm}^{2} / \mathrm{g}$ \\
\hline \multicolumn{2}{|l|}{ Expansibilidade a quente } & $0,8 \mathrm{~mm}$ & $\leq 5,0 \mathrm{~mm}$ \\
\hline \multicolumn{2}{|c|}{ Água de pasta de consistência } & $26,6 \%$ & Não aplicável \\
\hline \multirow{2}{*}{ Finura } & $\# 200$ & $2,0 \%$ & $\leq 12,0 \%$ \\
\hline & $\# 325$ & $7,5 \%$ & Não aplicável \\
\hline \multirow{2}{*}{ Tempo de pega } & Início & $181 \mathrm{~min}$ & $\geq 60 \mathrm{~min}$ \\
\hline & Fim & $235 \mathrm{~min}$ & $\leq 600 \mathrm{~min}$ \\
\hline \multirow{3}{*}{ Resistência à compressão } & 3 dias & $25,1 \mathrm{MPa}$ & $\geq 10,0 \mathrm{MPa}$ \\
\hline & 7 dias & $32,3 \mathrm{MPa}$ & $\geq 20,0 \mathrm{MPa}$ \\
\hline & 28 dias & $40,4 \mathrm{MPa}$ & $\geq 32,0$ e $\leq 49,0$ \\
\hline
\end{tabular}

Fonte: Votorantim Cimentos (2017).

${ }^{1}$ Denomina-se arisco a areia fina rica em materiais argilosos, bastante utilizada no estado do Ceará, também conhecida como saibro. 
Figura 5 - Agregados naturais e reciclados

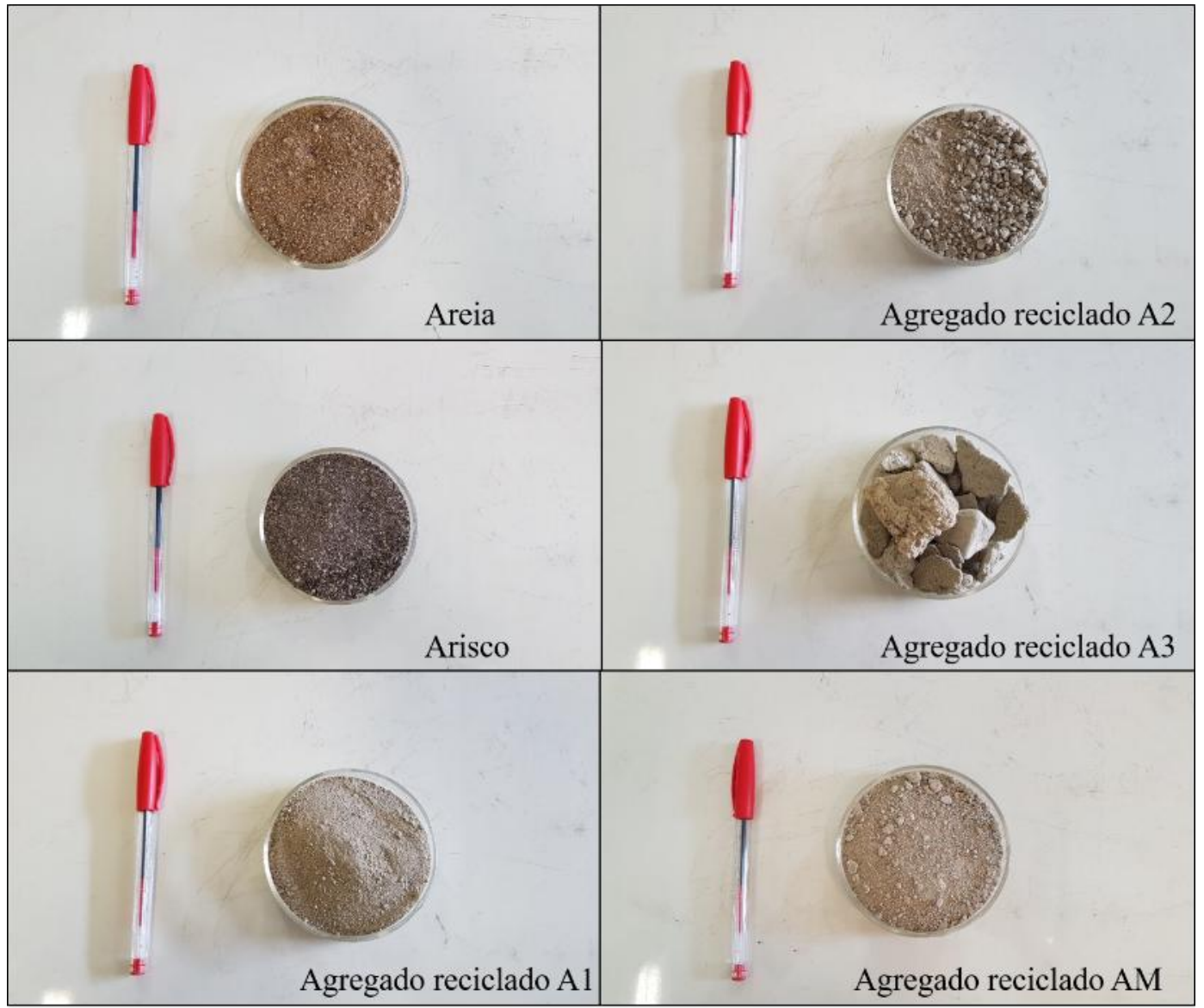

Figura 6 - Granulometria de areia natural e dos agregados reciclados

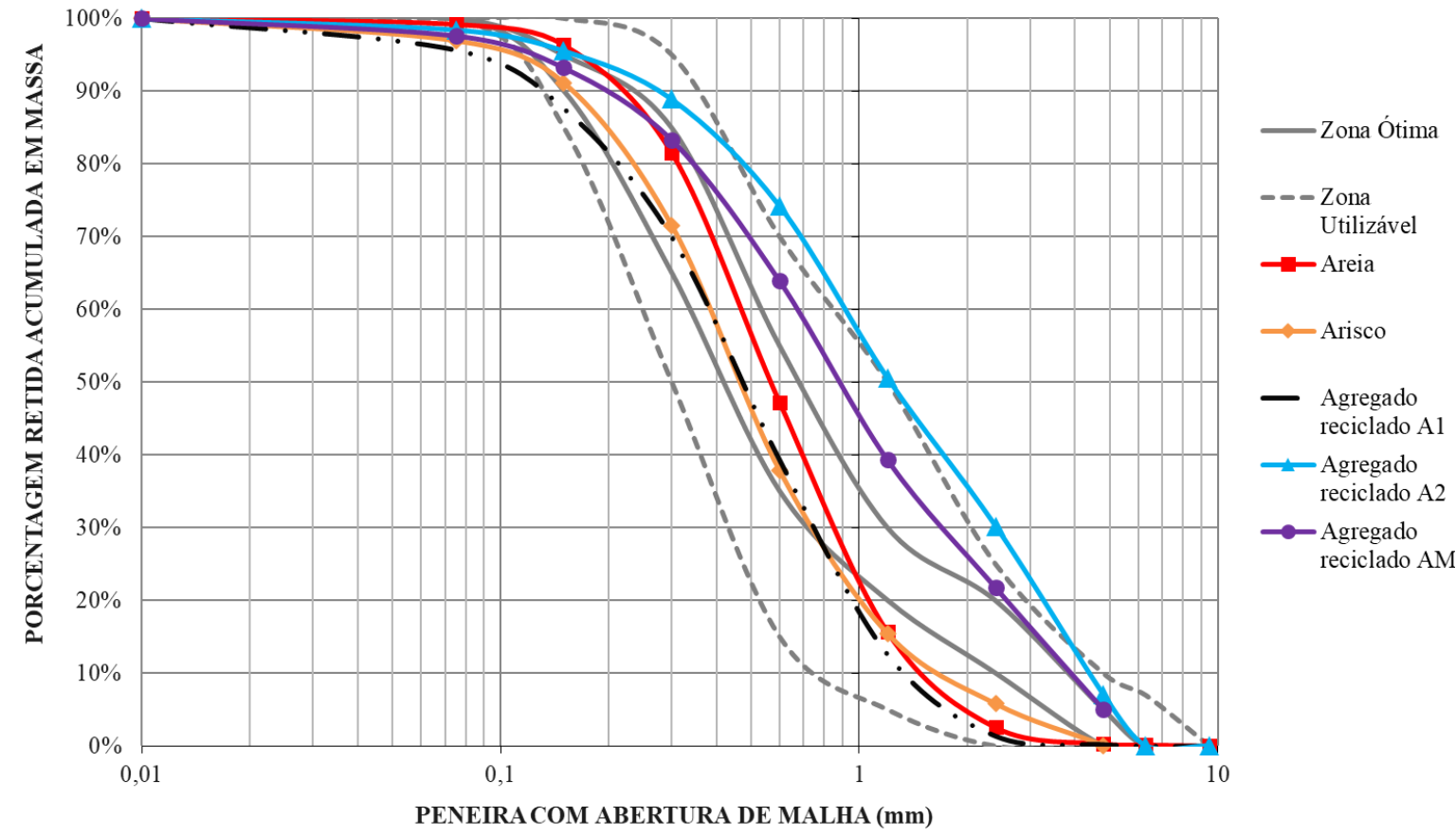

370 Santos, D. V.; Cabral, A. E. B. 
Tabela 7 - Dimensões em percentuais principais de areias e agregados reciclados

\begin{tabular}{l|c|c|c}
\hline \multicolumn{1}{c|}{ Material } & D10 & D50 & D90 \\
\hline Areia & $1,2 \mathrm{~mm}$ & $0,3 \mathrm{~mm}$ & $0,15 \mathrm{~mm}$ \\
Arisco & $1,2 \mathrm{~mm}$ & $0,3 \mathrm{~mm}$ & $0,15 \mathrm{~mm}$ \\
Agregado reciclado A1 & $1,2 \mathrm{~mm}$ & $0,3 \mathrm{~mm}$ & $0,075 \mathrm{~mm}$ \\
Agregado reciclado A2 & $2,4 \mathrm{~mm}$ & $1,2 \mathrm{~mm}$ & $0,15 \mathrm{~mm}$ \\
Agregado reciclado AM & $2,4 \mathrm{~mm}$ & $0,6 \mathrm{~mm}$ & $0,15 \mathrm{~mm}$ \\
\hline
\end{tabular}

Tabela 8 - Caracterização de agregados naturais e reciclados

\begin{tabular}{|c|c|c|c|c|c|c|}
\hline Parâmetro & Norma técnica & Areia & Arisco & $\begin{array}{l}\text { Agregado } \\
\text { reciclado } \\
\mathbf{A 1} \\
\end{array}$ & $\begin{array}{c}\text { Agregado } \\
\text { reciclado } \\
\text { A2 } \\
\end{array}$ & $\begin{array}{c}\text { Agregado } \\
\text { reciclado } \\
\text { AM }\end{array}$ \\
\hline $\begin{array}{l}\text { Dimensão } \\
\text { máxima } \\
\text { característica }\end{array}$ & $\begin{array}{l}\text { NBR NM } 248 \\
(\mathrm{ABNT}, 2003 \mathrm{a})\end{array}$ & 2,36 & 4,75 & 4,75 & 6,30 & 4,75 \\
\hline $\begin{array}{l}\text { Módulo de } \\
\text { finura }\end{array}$ & $\begin{array}{l}\text { NBR NM } 248 \\
(\text { ABNT, 2003a) }\end{array}$ & 2,44 & 2,22 & 2,11 & 3,46 & 3,07 \\
\hline $\begin{array}{l}\text { Massa } \\
\text { específica } \\
\left(\mathrm{g} / \mathrm{cm}^{3}\right)\end{array}$ & $\begin{array}{c}\text { NBR NM } 52 \\
(\mathrm{ABNT}, 2009 \mathrm{q}) \text { e NBR } \\
16605(\mathrm{ABNT}, 2017)\end{array}$ & 2,60 & 2,50 & 2,64 & 2,64 & 2,64 \\
\hline $\begin{array}{l}\text { Massa unitária } \\
\text { no estado solto } \\
\left(\mathrm{g} / \mathrm{cm}^{3}\right)\end{array}$ & $\begin{array}{l}\text { NBR NM } 45 \\
(A B N T, 2006)\end{array}$ & 1,44 & 1,38 & 1,40 & 1,33 & 1,36 \\
\hline Absorção & $\begin{array}{l}\text { NBR NM } 30 \\
(\text { ABNT, 2001) }\end{array}$ & $0,8 \%$ & $0,8 \%$ & $7,1 \%$ & $6,2 \%$ & $7,2 \%$ \\
\hline $\begin{array}{l}\text { Teor de } \\
\text { material } \\
\text { pulverulento }\end{array}$ & $\begin{array}{c}\text { NBR NM } 46 \\
(\mathrm{ABNT}, 2003 \mathrm{~b})\end{array}$ & $2,7 \%$ & $12,1 \%$ & $7,5 \%$ & $4,2 \%$ & $5,9 \%$ \\
\hline
\end{tabular}

A Tabela 8 apresenta a caracterização da areia utilizada pela construtora na confecção de argamassas e dos agregados reciclados A1, A2 e AM (mistura dos agregados reciclados A1 e A2). Observa-se que os valores de massa específica, massa unitária e absorção estão em consonância com os estudos apresentados neste artigo e que o teor de material pulverulento e a absorção de água estão abaixo dos limites máximos estabelecidos pela NBR 15116 (ABNT, 2004), à exceção do arisco. Nota-se ainda que a dimensão máxima característica do agregado reciclado A2 foi acima de $4,75 \mathrm{~mm}$, portanto acima do limite para consideração de agregado miúdo, entretanto se destaca que, em sua curva granulométrica, o percentual retido na peneira supracitada foi de $7 \%$, apenas $2 \%$ acima do limite para agregado miúdo.

Foi realizada também análise por imagem da forma e da angularidade da areia e do resíduo utilizados nos traços. Na Figura 7 mostram-se algumas imagens dos agregados geradas pelo AIMS, por faixa granulométrica. Na Tabela 9 apresentam-se os valores médios observados no ensaio supracitado, enquanto nas Tabelas 10 e 11 ilustra-se respectivamente a classificação dos agregados supracitados em sua forma 2D e angularidade. Nota-se claramente que os agregados apresentam características similares quanto a esses aspectos, sendo classificados como circulares e semicirculares na forma, e subarrendondados na angularidade.

\section{Resultados e discussões}

\section{Propriedades no estado fresco}

As Tabelas 12, 13 e 14 apresentam respectivamente as quantidades de material em quilograma por metro cúbico de argamassa, os resultados das propriedades supracitadas e a análise de variância do teor de ar incorporado e de densidade de massa no estado fresco.

Observa-se que, para o teor de ar incorporado, a variação em função do teor de substituição de areia natural por agregado reciclado é significativa. Pandolfo e Masuero (2005), Silva (2006), Guacelli (2010) e Freitas e Costa (2010) destacam que o maior teor de material pulverulento justifica esse fato. Todavia, esperava-se 
redução dos valores de teor de ar incorporado com o aumento de agregado reciclado, uma vez que o agregado reciclado apresenta maior teor de material pulverulento, o que reduziria os vazios da argamassa. Esse fato só foi observado para os traços de emboço interno. Já para densidade de massa no estado fresco, observou-se insignificância para variações do teor de substituição.

Figura 7 - Imagens dos agregados geradas pelo AIMS

\begin{tabular}{|c|c|c|c|c|c|c|}
\hline \multicolumn{7}{|c|}{ Areia natural } \\
\hline
\end{tabular}

Tabela 9 - Resultados da caracterização geral dos agregados avaliados - AIMS

\begin{tabular}{l|l|c|c|c|c}
\hline \multirow{2}{*}{ Propriedade } & \multicolumn{2}{|c}{ Agregado } & \multirow{3}{*}{ Parâmetro estatístico } \\
\cline { 3 - 6 } & & Média & $\begin{array}{c}\text { Número de } \\
\text { partículas }\end{array}$ & $\begin{array}{c}\text { Desvio } \\
\text { padrão }\end{array}$ & \multirow{2}{*}{ CV (\%) } \\
\hline \multirow{2}{*}{ Forma 2D } & Areia natural & 7,48 & 937 & 1,99 & 26,6 \\
\cline { 2 - 6 } & Agregado reciclado AM & 7,16 & 928 & 1,88 & 26,3 \\
\hline \multirow{2}{*}{ Angularidade } & Areia natural & $3.003,30$ & 940 & $1.281,30$ & 42,7 \\
\cline { 2 - 6 } & Agregado reciclado AM & $3.293,80$ & 928 & $1.465,00$ & 44,5 \\
\hline
\end{tabular}

Tabela 10 - Classificação da forma dos agregados

\begin{tabular}{l|c|c|c|c}
\hline \multirow{2}{*}{ Agregado } & \multicolumn{4}{c}{ Concentração (\%) } \\
\cline { 2 - 5 } & Circular & Semicircular & Semialongado & Alongado \\
\hline Areia natural & $34 \%$ & $33 \%$ & $27 \%$ & $6 \%$ \\
Agregado reciclado AM & $40 \%$ & $32 \%$ & $23 \%$ & $5 \%$ \\
\hline
\end{tabular}

Tabela 11 - Classificação da angularidade dos agregados

\begin{tabular}{l|c|c|c|c}
\hline \multirow{2}{*}{ Agregado } & \multicolumn{4}{c}{ Concentração (\%) } \\
\cline { 2 - 5 } & Arredondado & Subarredondado & Subangular & Angular \\
\hline Areia natural & $18 \%$ & $56 \%$ & $19 \%$ & $7 \%$ \\
Agregado reciclado AM & $25 \%$ & $44 \%$ & $23 \%$ & $9 \%$ \\
\hline
\end{tabular}


Tabela 12 - Quantidade de materiais em quilograma por metro cúbico de argamassa

\begin{tabular}{l|l|c|c|c|c|c|c}
\hline $\begin{array}{c}\text { Tipo de } \\
\text { argamassa }\end{array}$ & $\begin{array}{c}\text { Teor de } \\
\text { substituição }\end{array}$ & $\begin{array}{c}\text { Cimento } \\
\left(\mathbf{k g} / \mathbf{m}^{3}\right)\end{array}$ & $\begin{array}{c}\text { Cal } \\
\left(\mathbf{k g} / \mathbf{m}^{3}\right)\end{array}$ & $\begin{array}{c}\text { Arisco } \\
\left(\mathbf{k g} / \mathbf{m}^{3}\right)\end{array}$ & $\begin{array}{c}\text { Areia } \\
\left(\mathbf{k g} / \mathbf{m}^{3}\right)\end{array}$ & $\begin{array}{c}\text { Agregado } \\
\text { reciclado } \\
\mathbf{A M}\left(\mathbf{k g} / \mathbf{m}^{3}\right)\end{array}$ & $\begin{array}{c}\text { Água } \\
\left(\mathbf{k g} / \mathbf{m}^{3}\right)\end{array}$ \\
\hline \multirow{2}{*}{ Contrapiso } & Referência & 351,18 & 0,00 & 0,00 & $1.615,83$ & 0,00 & 263,39 \\
\cline { 2 - 8 } & $\begin{array}{l}25 \% \text { de } \\
\text { substituição }\end{array}$ & 351,18 & 0,00 & 0,00 & $1.211,87$ & 410,17 & 263,39 \\
\cline { 2 - 8 } & $\begin{array}{l}50 \% \text { de } \\
\text { substituição }\end{array}$ & 345,12 & 0,00 & 0,00 & 793,97 & 806,19 & 276,10 \\
\hline \multirow{2}{*}{$\begin{array}{l}\text { Emboço } \\
\text { interno }\end{array}$} & $\begin{array}{l}\text { Referência } \\
\text { 25\% de } \\
\text { substituição }\end{array}$ & 269,89 & 0,00 & 648,79 & 993,46 & 0,00 & 269,89 \\
\hline \multirow{2}{*}{$\begin{array}{l}\text { Emboço } \\
\text { externo }\end{array}$} & $\begin{array}{l}\text { 50\% de } \\
\text { substituição }\end{array}$ & 262,80 & 0,00 & 631,74 & 483,67 & 491,12 & 289,08 \\
\cline { 2 - 8 } & $\begin{array}{l}\text { Referência } \\
\text { 25\% de } \\
\text { substituição }\end{array}$ & 261,41 & 104,56 & 0,00 & $1.443,35$ & 0,00 & 313,69 \\
\cline { 2 - 8 } & $\begin{array}{l}50 \% \text { de } \\
\text { substituição }\end{array}$ & 258,04 & 103,22 & 0,00 & $1.068,55$ & 361,66 & 322,55 \\
\hline
\end{tabular}

Tabela 13 - Propriedades das argamassas no estado fresco

\begin{tabular}{|c|c|c|c|c|}
\hline $\begin{array}{c}\text { Tipo de } \\
\text { argamassa }\end{array}$ & $\begin{array}{c}\text { Teor de } \\
\text { substituição }\end{array}$ & $\begin{array}{c}\text { Consistência } \\
(\mathbf{m m})\end{array}$ & $\begin{array}{c}\text { Teor de ar } \\
\text { incorporado }(\%)\end{array}$ & $\begin{array}{l}\text { Densidade de } \\
\text { massa }\left(\mathrm{g} / \mathrm{cm}^{3}\right)\end{array}$ \\
\hline Contrapiso & $\begin{array}{l}\text { Referência } \\
25 \% \text { de substituição } \\
50 \% \text { de substituição }\end{array}$ & $\begin{array}{l}156,2 \\
142,0 \\
144,3\end{array}$ & $\begin{array}{l}10,03 \\
13,82 \\
12,77\end{array}$ & $\begin{array}{l}2,01 \\
1,93 \\
1,94\end{array}$ \\
\hline Emboço interno & $\begin{array}{l}\text { Referência } \\
25 \% \text { de substituição } \\
50 \% \text { de substituição }\end{array}$ & $\begin{array}{l}200,0 \\
200,7 \\
191,7\end{array}$ & $\begin{array}{l}8,32 \\
6,59 \\
5,09\end{array}$ & $\begin{array}{l}2,03 \\
2,03 \\
2,05\end{array}$ \\
\hline Emboço externo & $\begin{array}{l}\text { Referência } \\
25 \% \text { de substituição } \\
50 \% \text { de substituição }\end{array}$ & $\begin{array}{l}268,0 \\
268,3 \\
264,7\end{array}$ & $\begin{array}{l}1,73 \\
4,10 \\
6,01 \\
\end{array}$ & $\begin{array}{l}2,09 \\
2,03 \\
1,98\end{array}$ \\
\hline
\end{tabular}

Tabela 14 - Análise de variância de teor de ar incorporado

\begin{tabular}{l|c|c|c|c}
\hline \multicolumn{1}{c|}{ Propriedade } & F & Valor P & F crítico & Resultado \\
\hline Teor de ar incorporado & 11,64758 & 0,021476 & 6,944272 & S \\
Densidade de massa no estado fresco & 2 & 0,25 & 6,944272 & NS \\
\hline
\end{tabular}

\section{Propriedades no estado endurecido}

Os valores médios de resistência à tração na flexão e à compressão aos 7 e 28 dias, e as análises de variância estão apresentados respectivamente nas Tabelas 15 e 16.

Observou-se elevação da resistência à tração na flexão com o teor de substituição de $25 \%$, com exceção do traço de emboço externo. Já na propriedade de resistência à compressão, observou-se comportamento semelhante, com exceção da idade de 7 dias para o traço de revestimento interno e para as idades de 7 e 28 dias para o traço de revestimento externo. Para o teor de substituição de $50 \%$, o comportamento foi semelhante ao observado com o teor de substituição de $25 \%$ em relação aos traços de referência, divergindo apenas na idade de 7 dias para a propriedade de resistência à tração na flexão para os traços de contrapiso e revestimento interno, nos quais foi observada redução de resistência. As variações ocorreram em até $38 \%$ em relação à referência. 
Tabela 15 - Propriedades das argamassas no estado endurecido

\begin{tabular}{|c|c|c|c|c|c|}
\hline $\begin{array}{c}\text { Tipo de } \\
\text { argamassa }\end{array}$ & $\begin{array}{c}\% \text { de } \\
\text { substituição }\end{array}$ & $\begin{array}{c}\text { Resistência à } \\
\text { tração na } \\
\text { flexão }-7 \\
\text { dias (MPa) }\end{array}$ & $\begin{array}{c}\text { Resistência à } \\
\text { tração na } \\
\text { flexão - 28 } \\
\text { dias (MPa) }\end{array}$ & $\begin{array}{c}\text { Resistência à } \\
\text { compressão -7 } \\
\text { dias (MPa) }\end{array}$ & $\begin{array}{c}\text { Resistência à } \\
\text { compressão -28 } \\
\text { dias (MPa) }\end{array}$ \\
\hline \multirow{3}{*}{ Contrapiso } & Referência & 2,9 & 3,4 & 9,0 & 11,4 \\
\hline & $\begin{array}{c}25 \% \text { de } \\
\text { substituição }\end{array}$ & 3,4 & 4,0 & 10,7 & 12,7 \\
\hline & $\begin{array}{c}50 \% \text { de } \\
\text { substituição }\end{array}$ & 2,8 & 4,7 & 10,3 & 14,2 \\
\hline \multirow{3}{*}{$\begin{array}{l}\text { Revestimento } \\
\text { interno }\end{array}$} & Referência & 2,6 & 3,3 & 8,2 & 10,1 \\
\hline & $\begin{array}{c}25 \% \text { de } \\
\text { substituição }\end{array}$ & 2,9 & 3,7 & 7,8 & 12,2 \\
\hline & $\begin{array}{c}50 \% \text { de } \\
\text { substituição }\end{array}$ & 2,4 & 3,6 & 8,1 & 12,3 \\
\hline \multirow{3}{*}{$\begin{array}{l}\text { Revestimento } \\
\text { externo }\end{array}$} & Referência & 2,0 & 4,6 & 6,8 & 10,9 \\
\hline & $\begin{array}{c}25 \% \text { de } \\
\text { substituição }\end{array}$ & 1,8 & 4,2 & 6,4 & 10,3 \\
\hline & $\begin{array}{c}50 \% \text { de } \\
\text { substituição }\end{array}$ & 1,6 & 3,8 & 5,7 & 9,2 \\
\hline
\end{tabular}

Tabela 16 - Análise de variância de resistência de tração na flexão e de compressão aos 7 e aos 28 dias

\begin{tabular}{|c|c|c|c|c|c|c|}
\hline Propriedade & Idade & Tipo de argamassa & $\mathbf{F}$ & Valor $\mathbf{P}$ & F crítico & Resultado \\
\hline \multirow{6}{*}{$\begin{array}{l}\text { Resistência de } \\
\text { tração na flexão }\end{array}$} & \multirow{3}{*}{7 dias } & Contrapiso & 2,838775 & 0,17084 & 6,944272 & NS \\
\hline & & Revestimento interno & 4,920845 & 0,065874 & 5,786135 & NS \\
\hline & & Revestimento externo & 2,361753 & 0,189613 & 5,786135 & NS \\
\hline & \multirow{3}{*}{28 dias } & Contrapiso & 8,159329 & 0,019429 & 5,143253 & $\mathrm{~S}$ \\
\hline & & Revestimento interno & 1,257295 & 0,349915 & 5,143253 & NS \\
\hline & & Revestimento externo & 1,246211 & 0,403679 & 9,552094 & NS \\
\hline \multirow{6}{*}{$\begin{array}{l}\text { Resistência à } \\
\text { compressão }\end{array}$} & \multirow{3}{*}{7 dias } & Contrapiso & 63,10987 & $9,37 \mathrm{E}-07$ & 3,982298 & $\mathrm{~S}$ \\
\hline & & Revestimento interno & 2,84270 & 0,09202 & 3,73889 & NS \\
\hline & & Revestimento externo & 30,5942 & $1,21 \mathrm{E}-5$ & 3,80557 & $\mathrm{~S}$ \\
\hline & \multirow{3}{*}{28 dias } & Contrapiso & 22,72776 & 0,000303 & 4,256495 & $\mathrm{~S}$ \\
\hline & & Revestimento interno & 10,154325 & 0,004927 & 4,256495 & $\mathrm{~S}$ \\
\hline & & Revestimento externo & 22,2753 & 0,00054 & 4,45897 & $\mathrm{~S}$ \\
\hline
\end{tabular}

Porém, conforme análises de variância para as idades de 7 e 28 dias ilustradas na Tabela 16, os dados apresentam significância para resistência à tração na flexão quanto à variação de teores de substituição somente para o traço de contrapiso para a idade de 28 dias. Já para a resistência à compressão, a Tabela 16 mostra que os dados apresentam significância para quase todos os casos, excetuando-se apenas a idade de 7 dias para o traço de revestimento interno. Considerando os requisitos propostos pela NBR 13281 (ABNT, 2005e), observa-se que todas as argamassas estudadas são classificadas como P6 no critério de resistência à compressão e como R5 no critério de resistência à tração na flexão. Portanto, a substituição da areia natural por agregado reciclado foi positiva para as propriedades mecânicas de resistência à tração na flexão e à compressão.

Destaca-se ainda que os valores observados nos traços de referência são similares aos observados nos estudos de Silva (2014). O acréscimo de resistência à tração na flexão com a substituição de agregado natural por reciclado também foi notado nos estudos de Santana, Araújo e Pereira (2017), Neno (2010) e Silva e Campiteli (2008). Ledesma et al. (2014) e Jiménez et al. (2013) obtiveram melhor resultado nesse aspecto para as argamassas com até 50\% de substituição. Porém, os trabalhos de Martinez et al. (2018), Saiz Martínez et al. (2016) e Stefanidou, Anastasiou e Georgiadis Filikas (2014) ilustram a redução da resistência à tração na flexão. Essa propriedade varia conforme a origem do agregado reciclado. Nota-se, no caso, que, para agregados reciclados provenientes de concreto, argamassa e cerâmica, as argamassas apresentam condições satisfatórias de uso, considerando a resistência à tração na flexão.

374 Santos, D. V.; Cabral, A. E. B. 
Em se tratando de resistência à compressão, para contrapiso e emboço interno a argamassa mais resistente foi a que continha $50 \%$ de substituição, enquanto para emboço externo o melhor foi o traço de referência. Não se observaram variações significativas apenas para emboço interno na idade de 7 dias.

O acréscimo de resistência à compressão com a substituição de agregado natural por reciclado também foi notado nos estudos de Martinez et al. (2018), Santana, Araújo e Pereira (2017), Morales (2015), Silva (2014), Stefanidou, Anastasiou e Georgiadis Filikas (2014), Oliveira e Cabral (2011), Morais (2011) e Neno (2010). Porém, os trabalhos de Saiz Martínez et al. (2016), Jiménez et al. (2013) e Martinez et al. (2013) ilustram a redução da resistência à compressão com a elevação do teor de substituição, emboraainda em valores adequados à finalidade da argamassa. Analogamente ao observado para resistência à tração na flexão, Ledesma et al. (2014) e Jiménez et al. (2013) obtiveram melhor resultado nesse aspecto para as argamassas com até $50 \%$ de substituição.

O efeito de elevação da resistência à compressão com a substituição da areia natural por agregado reciclado era esperado para o tipo de agregado reciclado analisado neste trabalho. Entretanto, como já explanado, não ocorreu para o emboço externo. Provavelmente a piora no empacotamento gerado pelo efeito combinado da presença de cal nesse traço e o fato de o agregado reciclado ter maiores dimensões em relação à areia natural e maior presença de materiais pulverulentos possam explicar isso.

Os resultados de densidade de massa aparente e módulo de elasticidade dinâmico e da análise de variância dessas propriedades estão apresentados nas Tabelas 17 e 18 respectivamente.

Verificou-se que a densidade de massa aparente variou de $1.786,70 \mathrm{~kg} / \mathrm{m}^{3}$ a $1.942,76 \mathrm{~kg} / \mathrm{m}^{3} \mathrm{em}$ média e que o módulo de elasticidade dinâmico variou de 13,6 GPa a 18,5 GPa. Com base nas análises de variâncias apresentadas na Tabela 18, comprovou-se que a substituição do agregado natural pelo reciclado, nos teores testados, alterou significativamente os resultados da densidade de massa aparente para todos os traços e do módulo de elasticidade dinâmico para os traços de contrapiso e emboço interno.

Nota-se para os traços de contrapiso e emboço interno aumento da densidade de massa aparente até a substituição de $25 \%$ da areia natural pelo agregado reciclado, com posterior redução para o teor de $50 \%$. Isso não era esperado em virtude do fato de as resistências à tração na flexão e à compressão aos 28 dias terem sido maiores para o teor de 50\% de substituição. Girardi (2016), Hawlitschek et al. (2013) e Mendes e Borja (2007) observaram em seus estudos que há tendência do aumento da densidade com a elevação do teor de substituição do agregado natural por agregado reciclado.

Tabela 17 - Densidade de massa aparente e módulo de elasticidade dinâmico

\begin{tabular}{|c|c|c|c|}
\hline $\begin{array}{c}\text { Tipo de } \\
\text { argamassa }\end{array}$ & Traço & $\begin{array}{l}\text { Densidade de massa } \\
\text { aparente }\left(\mathrm{kg} / \mathrm{m}^{3}\right)\end{array}$ & $\begin{array}{l}\text { Módulo de elasticidade } \\
\text { dinâmico (GPa) }\end{array}$ \\
\hline Contrapiso & $\begin{array}{l}\text { Referência } \\
25 \% \text { de substituição } \\
50 \% \text { de substituição }\end{array}$ & $\begin{array}{l}1.887,41 \\
1.907,06 \\
1.822,96\end{array}$ & $\begin{array}{l}16,7 \\
18,5 \\
17,9\end{array}$ \\
\hline $\begin{array}{l}\text { Emboço } \\
\text { interno }\end{array}$ & $\begin{array}{l}\text { Referência } \\
25 \% \text { de substituição } \\
50 \% \text { de substituição }\end{array}$ & $\begin{array}{l}1.865,89 \\
1.942,76 \\
1.891,43 \\
\end{array}$ & $\begin{array}{l}13,6 \\
15,3 \\
15,7 \\
\end{array}$ \\
\hline $\begin{array}{l}\text { Emboço } \\
\text { externo }\end{array}$ & $\begin{array}{l}\text { Referência } \\
25 \% \text { de substituição } \\
50 \% \text { de substituição }\end{array}$ & $\begin{array}{l}1.912,31 \\
1.797,45 \\
1.786,70\end{array}$ & $\begin{array}{l}14,1 \\
14,4 \\
14,0\end{array}$ \\
\hline
\end{tabular}

Tabela 18 - Análise de variância de densidade de massa aparente no estado endurecido

\begin{tabular}{l|l|c|c|c|c}
\hline \multicolumn{1}{c|}{ Propriedade } & \multicolumn{1}{|c|}{ Tipo de argamassa } & F & Valor P & F crítico & Resultado \\
\hline \multirow{2}{*}{$\begin{array}{l}\text { Densidade de massa } \\
\text { aparente }\end{array}$} & Contrapiso & 19,949906 & 0,008302 & 6,944272 & $\mathrm{~S}$ \\
\cline { 2 - 6 } & Revestimento interno & 19,706467 & 0,018812 & 9,552094 & $\mathrm{~S}$ \\
\cline { 2 - 6 } & Revestimento externo & 18,727768 & 0,009310 & 6,944272 & $\mathrm{~S}$ \\
\hline \multirow{2}{*}{$\begin{array}{l}\text { Módulo de } \\
\text { elasticidade dinâmico }\end{array}$} & Contrapiso & 50,057724 & 0,004962 & 9,552094 & $\mathrm{~S}$ \\
\cline { 2 - 6 } & Revestimento interno & 30,704423 & 0,003740 & 6,944272 & $\mathrm{~S}$ \\
\cline { 2 - 6 } & Revestimento externo & 0,217762 & 0,816004 & 9,552094 & $\mathrm{NS}$ \\
\hline
\end{tabular}


Para o módulo de elasticidade dinâmico, houve tendência de aumento com a elevação do teor de substituição do agregado natural pelo reciclado nos traços de contrapiso e emboço interno. Esse fato é coerente em virtude do comportamento das resistências à tração na flexão e à compressão observado para essas argamassas nas Figuras 26 e 27. Situação análoga foi observada por Silva e Campiteli (2008). Já para o traço de emboço externo, essa tendência somente se observou até o teor de $25 \%$ de substituição, analogamente ao trabalho de Levy e Helene (1997), que observaram aumento do teor de substituição de agregado natural por agregado reciclado proveniente de argamassa, com a consequente redução do módulo de elasticidade dinâmico.

Destaca-se que as propriedades de densidade de massa aparente e módulo de elasticidade dinâmico são bastante correlacionadas. Porém, os resultados neste estudo não apresentam essas correlações de variação conforme esperado. Infere-se que tenha ocorrido alguma inconsistência na realização dos ensaios supracitados, o que gerou essa incongruência.

\section{Propriedades na argamassa de revestimento}

As Tabelas 19 e 20 mostram respectivamente as propriedades das argamassas de revestimento e a análise de variância realizada para a propriedade de resistência de aderência à tração.

Nota-se que os traços referência de emboço interno e externo possuem as maiores fissurações, enquanto os traços com substituição de areia por resíduo AM apresentam menores fissurações.

Angelim, Angelim e Carasek (2003) destacam que a maior presença de finos acarreta a elevação da fissuração. No entanto, essa influência do teor de finos total varia de acordo com a natureza mineralógica da adição. Além disso, a relação água-cimento é importante para o grau de fissuração. Quanto maior essa relação, mais elevada será a probabilidade de se observar fissuração (GIRARDI, 2016). Ledesman et al. (2014), Jímenez et al. (2013) e Miranda (2005) associam os agregados reciclados à fissuração. Todavia, destacam ainda que cabe uma maior investigação sobre o tipo e a quantidade de agregados reciclados e a fissuração do sistema. Para Kazmierczak, Rosa e Arnold (2016), para teores de finos entre 6\% e 10\%, permite-se a obtenção de argamassa sem fissuração por retração, fato observado neste trabalho, uma vez que o teor de finos do agregado reciclado AM foi de 5,9\%.

Nota-se para permeabilidade à água pequena variação para os traços com $50 \%$ de substituição no emboço interno. Já para o teor de substituição de $25 \%$, observa-se praticamente igualdade nos dados. Em termos de valores absolutos, esses resultados foram menores do que os observados por Sampaio (2017) e Girardi (2016), e similares aos observados por Lapa (2011).

Tabela 19 - Propriedades das argamassas de revestimento

\begin{tabular}{|c|c|c|c|c|c|c|c|}
\hline \multirow{2}{*}{$\begin{array}{c}\text { Tipo de } \\
\text { argamassa }\end{array}$} & \multirow{2}{*}{$\begin{array}{c}\% \text { de } \\
\text { substituição }\end{array}$} & \multicolumn{2}{|c|}{$\begin{array}{c}\text { Resistência de } \\
\text { aderência (MPa) }\end{array}$} & \multirow{2}{*}{$\begin{array}{l}\text { Fissuração } \\
\left(\mathbf{m} / \mathbf{m}^{2}\right)\end{array}$} & \multirow{2}{*}{$\begin{array}{c}\text { Menor } \\
\text { espessura de } \\
\text { fissura }(\mathbf{m m})\end{array}$} & \multirow{2}{*}{$\begin{array}{c}\text { Maior } \\
\text { espessura } \\
\text { de fissura } \\
(\mathbf{m m}) \\
\end{array}$} & \multirow{2}{*}{$\begin{array}{l}\text { Permeabili- } \\
\text { dade à água } \\
\text { (ml/min) }\end{array}$} \\
\hline & & Média & $\begin{array}{l}\text { Desvio } \\
\text { padrão }\end{array}$ & & & & \\
\hline \multirow{3}{*}{ Contrapiso } & Referência & 0,25 & 0,11 & 0,05 & 0,30 & 0,40 & $\begin{array}{c}\text { Não } \\
\text { aplicável }\end{array}$ \\
\hline & $\begin{array}{l}25 \% \text { de } \\
\text { substituição }\end{array}$ & 0,22 & 0,02 & 0,05 & 0,10 & 0,10 & $\begin{array}{c}\text { Não } \\
\text { aplicável }\end{array}$ \\
\hline & $\begin{array}{l}50 \% \text { de } \\
\text { substituição }\end{array}$ & 0,22 & 0,03 & 0,05 & 0,10 & 0,10 & $\begin{array}{c}\text { Não } \\
\text { aplicável }\end{array}$ \\
\hline \multirow{3}{*}{$\begin{array}{l}\text { Revesti- } \\
\text { mento } \\
\text { interno }\end{array}$} & Referência & 0,25 & 0,09 & 0,62 & 0,40 & 0,50 & 0,04 \\
\hline & $\begin{array}{l}25 \% \text { de } \\
\text { substituição }\end{array}$ & 0,29 & 0,17 & 0,22 & 0,10 & 0,30 & 0,04 \\
\hline & $\begin{array}{l}50 \% \text { de } \\
\text { substituição }\end{array}$ & 0,28 & 0,10 & 0,04 & 0,10 & 0,10 & 0,09 \\
\hline \multirow{3}{*}{$\begin{array}{l}\text { Revesti- } \\
\text { mento } \\
\text { externo }\end{array}$} & Referência & 0,20 & 0,05 & 1,74 & 0,30 & 0,40 & 0,08 \\
\hline & $\begin{array}{l}25 \% \text { de } \\
\text { substituição }\end{array}$ & 0,20 & 0,09 & 0,26 & 0,10 & 0,10 & 0,08 \\
\hline & $\begin{array}{l}50 \% \text { de } \\
\text { substituição }\end{array}$ & 0,28 & 0,13 & 0,63 & 0,10 & 0,10 & 0,07 \\
\hline
\end{tabular}

376 Santos, D. V.; Cabral, A. E. B. 
Tabela 20 - Análise de variância de resistência de aderência à tração

\begin{tabular}{l|l|c|c|c|c}
\hline \multicolumn{1}{c|}{ Propriedade } & Tipo de argamassa & F & Valor P & F crítico & Resultado \\
\hline \multirow{2}{*}{$\begin{array}{l}\text { Resistência de } \\
\text { aderência à tração }\end{array}$} & Contrapiso & 0,35395 & 0,70644 & 3,52189 & NS \\
\cline { 2 - 6 } & Revestimento interno & 0,32966 & 0,72193 & 3,34039 & NS \\
\cline { 2 - 6 } & Revestimento externo & 2,43576 & 0,10803 & 3,38519 & NS \\
\hline
\end{tabular}

A redução da permeabilidade com a elevação do teor de substituição da areia natural por agregado reciclado foi observada por Girardi (2016). Ferreira (2010) destaca que a quantidade de água no traço pode influenciar a permeabilidade de argamassa. Angelim, Angelim e Carasek (2003) mostraram que o aumento do teor de finos leva à redução da permeabilidade da argamassa. Portanto, considerando que a substituição do agregado natural por reciclado gera elevação na quantidade de água e aumento do teor de finos, o comportamento observado era esperado.

Em se tratando da aderência, as argamassas obtiveram valores médios acima do limite mínimo de 0,20 MPa, estabelecido pela NBR 13281 (ABNT, 2005e). Todavia, todos os traços de emboço externo ficaram abaixo de 0,30 MPa. Porém, nota-se que a substituição da areia natural por agregado reciclado não implicou redução dessa propriedade mecânica, o que denota claramente sua aplicabilidade.

Destaca-se ainda, com base na análise de variância realizada com esses dados e ilustrada na Tabela 20, que todos os valores não apresentaram significância em relação ao teor de substituição. Salienta-se que, em geral, resultados de ensaios de resistência de aderência à tração apresentam alta dispersão, levando a coeficientes de variação da ordem de $10 \%$ a $35 \%$, mas chegam muitas vezes à faixa de $50 \%$ a $60 \%$ (CARASEK, 2012). Isso se deve a diversos fatores, tais como material do substrato, características da argamassa, condições climáticas e energia de aplicação da argamassa (CARASEK, 2010).

\section{Conclusão}

Este artigo apresentou um estudo sobre a utilização de agregados reciclados provenientes de resíduos de concreto e argamassa, avaliando-se as propriedades dos agregados, as propriedades da argamassa nos estados fresco e endurecido, e os da argamassa de revestimento. As conclusões são:

(a) os agregados naturais e os reciclados apresentaram similaridade quanto à forma e à angularidade, além das propriedades de granulometria, DMC, módulo de finura, massa unitária e massa específica. Já em relação ao teor de material pulverulento e absorção, verificou-se variabilidade mais significativa, na ordem de 3,2\% e 6,4\% respectivamente do agregado reciclado AM em relação ao agregado natural. Destaca-se ainda que o teor de material pulverulento dos agregados reciclados A1, A2 e AM foi de respectivamente $7,5 \%, 4,2 \%$ e 5,9\%. Em todos os casos não superou os $10 \%$. Portanto, esse aspecto não impactaria negativamente a questão de fissuração;

(b) no que compete às propriedades no estado fresco, não se observou variabilidade significativa somente em relação à densidade de massa no estado fresco quanto a teores de substituição de areia natural por agregado reciclado. Notou-se aumento do teor de ar incorporado com a elevação do teor de substituição da areia natural pelo agregado reciclado nos traços de contrapiso e de emboço externo, enquanto no emboço interno o comportamento foi o oposto, mesmo que as densidades de massa no estado fresco não apresentassem variações significativas. Possivelmente maiores teores de água e de teor de finos nos traços com agregado reciclado tenham impactado na propriedade de teor de ar incorporado;

(c) em se tratando da densidade de massa aparente no estado endurecido, módulo de elasticidade dinâmico, resistência à tração na flexão, à compressão e de aderência, notou-se a existência de variação significativa em todas as propriedades, seja em um traço específico ou em uma idade de ruptura específica, com exceção da resistência de aderência à tração, que não apresentou variabilidade significativa para nenhum dos casos estudados. Nota-se como positivo que a aderência não foi impactada com o aumento do teor de substituição do agregado natural pelo reciclado e que, para resistência à compressão e à tração na flexão, embora tenha havido variações com o teor de substituição, todas as argamassas permaneceram na mesma classe de classificação quanto a essas propriedades, o que denota o fato de a argamassa apresentar desempenho semelhante quanto a essas características;

(d) no que compete à fissuração, verificou-se que as fissuras foram reduzidas com a substituição de areia natural por agregado reciclado em função do melhor empacotamento da argamassa com agregado reciclado e 
do fato de o teor de finos não ultrapassar 10\%. Logo, considerando essa restrição do teor de finos de $10 \%$, para fissuração, é viável o uso desse agregado reciclado proveniente de concretos e argamassas; e

(e) em relação à permeabilidade à água, não houve variação com a elevação do teor de substituição para emboço externo. Porém, notou-se elevação dessa propriedade para o traço de emboço interno com substituição de 50\% do agregado natural pelo reciclado. Os valores de permeabilidade à água foram considerados baixos, mesmo com essa elevação destacada anteriormente, o que se considera positivo. Destaca-se que seria interessante avaliar essas propriedades considerando variações de posição em relação à exposição a intempéries, do período do ano e de substrato para um melhor entendimento de seu comportamento.

Indica-se para futuros trabalhos:

(a) aumentar a base de dados para melhor avaliação do substrato, considerando variações de aplicações em blocos cerâmicos e de concreto, em estruturas, e até contemplando a presença ou não de juntas. Isso dará melhor entendimento do comportamento da argamassa, com vários percentuais de substituição de agregado natural por reciclado, em relação à aderência ao substrato;

(b) realizar mais ensaios de módulo de elasticidade dinâmico e de densidade de massa no estado endurecido para compreender a correlação dessas duas variáveis e o comportamento delas com o teor de substituição de agregado natural pelo reciclado; e

(c) estudar quais parâmetros devem ser utilizados para melhor controle de fissuração de argamassa, uma vez que isso impacta em seu desempenho físico e mecânico, além da questão da durabilidade.

\section{Referências}

AL ROUSAN, T. M. Characterization of aggregate shape properties using a computer automated system. 2004. 211 f. Tese (Doutorado em Engenharia Civil) - Office of Graduate Studies, Texas A\&M University, Texas, 2004.

AMERICAN ASSOCIATION OF HIGHWAY AND TRANSPORTATION OFFICIALS. Designation TP 81-10: standard method of test for determining aggregate shape properties by means of digital image analysis. Washington, 2012.

ANGELIM, R. R.; ANGELIM, S. C. M.; CARASEK, H. Influência da adição de finos calcários, silicosos e argilosos nas propriedades das argamassas e dos revestimentos. In: SIMPÓSIO BRASILEIRO DE TECNOLOGIA DAS ARGAMASSAS, São Paulo, 2003. Anais [...] São Paulo, 2003.

ASSOCIAÇÃO BRASILEIRA DE NORMAS TÉCNICAS. NBR 13276: argamassa para assentamento e revestimento de paredes e tetos: determinação do índice de consistência. Rio de Janeiro, 2016.

ASSOCIAÇÃO BRASILEIRA DE NORMAS TÉCNICAS. NBR 13278: argamassa para assentamento e revestimento de paredes e tetos: determinação da densidade de massa e do teor de ar incorporado. Rio de Janeiro, 2005a.

ASSOCIAÇÃO BRASILEIRA DE NORMAS TÉCNICAS. NBR 13279: argamassa para assentamento e revestimento de paredes e tetos: determinação da resistência à tração na flexão e à compressão. Rio de Janeiro, 2005c.

ASSOCIAÇÃO BRASILEIRA DE NORMAS TÉCNICAS. NBR 13280: argamassa para assentamento e revestimento de paredes e tetos: determinação da densidade de massa aparente no estado endurecido. Rio de Janeiro, 2005b.

ASSOCIAÇÃO BRASILEIRA DE NORMAS TÉCNICAS. NBR 13281: argamassa para assentamento e revestimento de paredes e tetos: requisitos. Rio de Janeiro, 2005e.

ASSOCIAÇÃO BRASILEIRA DE NORMAS TÉCNICAS. NBR 15116: agregados reciclados de resíduos sólidos da construção civil: utilização em pavimentação e preparo de concreto sem função estrutural Requisitos. Rio de Janeiro, 2004.

ASSOCIAÇÃO BRASILEIRA DE NORMAS TÉCNICAS. NBR 15258: argamassa para revestimento de paredes e tetos: determinação da resistência potencial de aderência à tração. Rio de Janeiro, 2005d.

378 Santos, D. V.; Cabral, A. E. B. 
ASSOCIAÇÃO BRASILEIRA DE NORMAS TÉCNICAS. NBR 15630: argamassa para assentamento e revestimento de paredes e tetos: determinação do módulo de elasticidade dinâmico através da propagação de onda ultra-sônica. Rio de Janeiro, 2008.

ASSOCIAÇÃO BRASILEIRA DE NORMAS TÉCNICAS. NBR 16605: cimento Portland e outros materiais em pó: determinação da massa específica. Rio de Janeiro, 2017.

ASSOCIAÇÃO BRASILEIRA DE NORMAS TÉCNICAS. NBR 7175: cal hidratada para argamassas: requisitos. Rio de Janeiro, 2003b.

ASSOCIAÇÃO BRASILEIRA DE NORMAS TÉCNICAS. NBR 7211: agregados para concreto: especificação. Rio de Janeiro, 2009b.

ASSOCIAÇÃO BRASILEIRA DE NORMAS TÉCNICAS. NBR NM 248: agregados: determinação da composição granulométrica. Rio de Janeiro, 2003a.

ASSOCIAÇÃO BRASILEIRA DE NORMAS TÉCNICAS. NBR NM 30: agregado miúdo: determinação da absorção de água. Rio de Janeiro, 2001.

ASSOCIAÇÃO BRASILEIRA DE NORMAS TÉCNICAS. NBR NM 45: agregados: determinação da massa unitária e do volume de vazios. Rio de Janeiro, 2006.

ASSOCIAÇÃO BRASILEIRA DE NORMAS TÉCNICAS. NBR NM 46: agregados: determinação do material fino que passa através da peneira $75 \mu \mathrm{m}$, por lavagem. Rio de Janeiro, 2003b.

ASSOCIAÇÃO BRASILEIRA DE NORMAS TÉCNICAS. NBR NM 52: agregado miúdo: determinação da massa específica e massa específica aparente. Rio de Janeiro, 2009a.

BRAGA, M.; BRITO, J.; VEIGA, R. Incorporation of fine concrete aggregates in mortars. Construction and Building Materials, v. 36, p. 960-968, 2012.

BRAVO, M. et al. Durability performance of concrete with recycled aggregates from construction and demolition waste plants. Construction and Building Materials, v. 77, p. 357-369, 2015a.

BRAVO, M. et al. Mechanical performance of concrete made with aggregates from construction and demolition waste recycling plants. Journal of Cleaner Production, v. 99, p. 59-74, 2015b.

CABRAL, A. E. B. Modelagem de propriedades mecânicas e de durabilidade de concretos produzidos com agregados reciclados, considerando-se a variabilidade da composição do RCD. 2007. 254 f. Tese (Doutorado em Engenharia Ambiental) - Escola de Engenharia de São Carlos, Universidade de São Paulo, São Carlos, 2007.

CARASEK, H. Argamassas. In: ISAIA, G. C. (org.). Materiais de construção civil e princípios de ciência e engenharia de materiais. 2. ed. São Paulo: Ibracon, 2010.

CARASEK, H. Avaliação de resultados do ensaio de resistência de aderência de revestimentos de argamassa. Téchne: Revista de Tecnologia da Construção, p. 64-69, 2012.

CARNEIRO, A. P. et al. Características do entulho e do agregado reciclado. In: RECICLAGEM de entulho para a produção de materiais de construção: projeto Entulho Bom. Salvador: Editora da Universidade Federal da Bahia, 2001.

CENTRE SCIENTIFIQUE ET TECHINIQUE DE LA CONSTRUCTION. Hydrofugue de surface: choix er mise em oeuvre. Centre Scientifique et Techinique de la Construction, v. 1, n. 1, p. 24, 1982.

CONTRERAS, M.et al. Recycling of construction and demolition waste for producing new construction material (Brazil case-study). Construction and Building Materials, v. 123, p. 594-600, 2016.

CORREIA, J. R.; BRITO, J.; PEREIRA, A. S. Effects on concrete durability of using recycled ceramic aggregates. Materials and Structures, v. 39, n. 2, p. 169-177, 2007.

ETXEBERRIA, M. et al. Influence of amount of recycled coarse aggregates and production process on properties of recycled aggregate concrete. Cement and Concrete Research, v. 37, n. 5, p. 735-742, 2007.

EVANGELISTA, L.; BRITO, J. Concrete with fine recycled aggregates: a review. European Journal of Environmental and Civil Engineering, v. 18, n. 2, p. 129-172, 2014.

EVANGELISTA, L.; BRITO, J. Mechanical behavior of concrete made with fine recycled concrete aggregates. Cement and Concrete Composites, v. 29, n. 5, p. 397-401, 2007. 
FAN, C. C. et al. The effects of different fine recycled concrete aggregates on the properties of mortar. Materials, v. 8, n. 5, p. 2658-2672, 2015.

FERREIRA, R. G. Engenharia econômica e avaliação de projetos de investimento: critérios de avaliação: financiamentos e benefícios fiscais: análise de sensibilidade e risco. São Paulo: Atlas, 2010.

FREITAS, C.; COSTA, M. R. M. M. Estudo da influência da distribuição granulométrica no desempenho de argamassas com areia britada. In: ENCONTRO NACIONAL DE TECNOLOGIA DO AMBIENTE CONSTRUÍDO, 13., Canela, 2010. Anais [...] Canela: ANTAC, 2010.

GIRARDI, A. C. C. Avaliação da substituição total de areia natural por RCD em revestimentos de argamassa. Goiânia, 2016. 130 f. Dissertação (Mestrado em Engenharia Civil) - Universidade Federal de Goiás, Goiânia, 2016.

GUACELLI, P. A. G. Substituição de areia natural por areia de britagem de rochas basálticas para argamassas de revestimento. Londrina, 2010. 166 f. Dissertação (Mestrado em Engenharia de Edificações e Saneamento) - Centro de Tecnologia e Urbanismo, Universidade Estadual de Londrina, Londrina, 2010.

HAWLITSCHEK, G. et al. Estudo da influência de areias recicladas a partir de resíduos de construção e demolição (RCD) em argamassas. In: SIMPÓSIO BRASILEIRO DE TECNOLOGIA DAS ARGAMASSAS, 10., Fortaleza, 2013. Anais [...] Fortaleza: Antac, 2013.

JIMÉNEZ, J. R. et al.Use of fine recycled aggregates from ceramic waste in masonry mortar manufacturing. Construction and Building Materials, v. 40, p. 679-690, 2013.

JOHN, V. M. et al. Strategies for innovation in construction waste management in Brazil. Cib World Building Congress, p. 1-11, 2004.

KAZMIERCZAK, C. de S.; ROSA, M.; ARNOLD, D. C. M. Influência da adição de filer de areia de britagem nas propriedades de argamassas de revestimento. Ambiente Construído, Porto Alegre, v. 16, n. 2, p. 7-19, abr./jun. 2016.

KHATIB, J. M. Properties of concrete incorporating fine recycled aggregate. Cement and Concrete Research, v. 35, n. 4, p. 763-769, 2005.

KOU, S. C.; POON, C. S.; WAN, H. W. Properties of concrete prepared with low-grade recycled aggregates. Construction and Building Materials, v. 36, p. 881-889, 2012.

LAPA, J. S. Utilização em argamassas do resíduo de construção oriundo do próprio canteiro de obra. Belo Horizonte, 2011. 132 f. Dissertação (Mestrado em Construção Civil) - Escola deEngenharia, Universidade Federal de Minas Gerais, Belo Horizonte, 2011.

LEDESMA, E. F. et al. Properties of masonry mortars manufactured with fine recycled concrete aggregates. Computers and Chemical Engineering, v. 71, p. 289-298, 2014.

LEVY, S. M.; HELENE, P. Vantagens e desvantagens de argamassas produzidas com entulho de obra, finamente moído. 1997. Boletim Técnico da Escola Politécnica da Universidade de São Paulo, Departamento de Engenharia de Construção Civil, BT/PCC/185, 1997.

LIMA, A. S.; CABRAL, A. E. B. Caracterização e classificação dos resíduos de construção civil da cidade de Fortaleza (CE). Engenharia Sanitária e Ambiental, v. 18, n. 2, p. 169-176, 2013.

LOVATO, P. S.; MENEGATTI, R. Influência da pré-umidificação do agregado reciclado deresíduos da construção civil nas propriedades de argamassas de revestimentos. In:SIMPÓSIO BRASILEIRO DE TECNOLOGIA DAS ARGAMASSAS, 9., Porto Alegre. Anais [...] Porto Alegre: 2015.

MARTÍNEZ, I. et al.A comparative analysis of the properties of recycled and natural aggregate in masonry mortars. Construction and Building Materials, v. 49, p. 384-392, 2013.

MARTÍNEZ, I. et al. Influence of Demolition Waste Fine Particles on the Properties of Recycled Aggregate Masonry Mortar. International Journal of Civil Engineering, v. 16, n. 9, p. 1213-1226, 2018.

MEDINA, C. et al. Effect of the constituents (asphalt, clay materials, floating particles and fines) of construction and demolition waste on the properties of recycled concretes. Construction and Building Materials, v. 79, p. 22-33, 2015.

MEJÍA, E. et al. Mineralogical characterization of urban construction and demolition waste: potential use as a nutrient source for degraded soils. WIT Transactions on Ecology and The Environment, v. 194, p. 399$413,2015$.

380 Santos, D. V.; Cabral, A. E. B. 
MENDES, B. S.; BORJA, E. V. de. Estudo experimental das propriedades físicas de argamassas com adição de resíduos de cerâmicas vermelhas recicladas. Revista Holos, v. 3, p. 43-51, 2007.

MIRANDA, L. F. R. Contribuição ao desenvolvimento da produção e controle de argamassas de revestimento com areia reciclada lavada de resíduos classe A da construção civil. São Paulo, 2005. 439 f. Tese (Doutorado em Engenharia Civil) - Escola Politécnica, Universidade de São Paulo, São Paulo, 2005.

MIRANDA, L. F. R.; SELMO, S. M. S. CDW recycled aggregate renderings: part II, Analysis of the effect of materials finer than $75 \mu \mathrm{m}$ under accelerated aging performance. Construction and Building Materials, v. 20, n. 9, p. 625-633, 2006.

MORAIS, T. A. Estudo do uso do agregado miúdo reciclado de concreto na produção de argamassa de revestimento vertical. Fortaleza, 2011. 134 f. Dissertação (Mestrado em Engenharia Civil: Estruturas e Construção Civil) - Programa de Pós-Graduação em Engenharia Civil, Universidade Federal do Ceará, Fortaleza, 2011.

MORALES, B. R. S. C. Avaliação da influência das frações de agregado reciclado nas propriedades das argamassas de revestimento. Florianópolis, 2015. 201 f. Dissertação (Mestrado em Engenharia Civil) Programa de Pós-Graduação em Engenharia Civil, Universidade Federal de Santa Catarina, Florianópolis, 2015.

NENO, C. J. F. Desempenho de argamassas com incorporação de agregados finos provenientes da trituração do betão. Lisboa, 2010. 168 f. Dissertação (Mestrado em Engenharia Civil) - Instituto Superior Técnico, Universidade Técnica de Lisboa, Lisboa, 2010.

NETO, J. C. M. Gestão dos resíduos sólidos de construção e demolição no Brasil. São Carlos: RiMa, 2005.

OLIVEIRA, M. E. D.; CABRAL, A. E. B. Argamassas de revestimento produzidas com agregados reciclados de Fortaleza/CE, Brasil. Engenharia Civil UM, v. 41, p. 21-34, 2011.

OLIVEIRA, M. J. E. Materiais descartados pelas obras de construção civil: estudo dos resíduos de concreto para reciclagem. Rio Claro, 2002. $191 \mathrm{f}$. Tese (Doutorado em Engenharia Civil) - Instituto de Geociências e Ciências Exatas, Universidade Estadual Paulista, Rio Claro, 2002.

OSSA, A.; GARCÍA, J. L.; BOTERO, E. Use of recycled construction and demolition waste (CDW) aggregates: a sustainable alternative for the pavement construction industry. Journal of Cleaner Production, v. 135, p. 379-386, 2016.

PANDOLFO, L. M.; MASUERO, A. B. Propriedades das argamassas de revestimento produzidas com areia natural e areia de basalto. In: SIMPÓSIO BRASILEIRO DE TECNOLOGIA DAS ARGAMASSAS, 6. 2005, Florianópolis e INTERNACIONAL SYMPOSIUM ON MORTARS TECHNOLOGY, 1. , Florianópolis, 2005. Anais [...] Florianópolis: ANTAC, 2005.

RICHARDSON, A.; COVENTRY, K.; BACON, J. Freeze/thaw durability of concrete with recycled demolition aggregate compared to virgin aggregate concrete. Journal of Cleaner Production, v. 19, n. 2-3, p. 272-277, 2011.

REHNI - Máquinas e Equipamentos. Q200 RI. Disponível em http://www.rehni.com.br/queixada-200p.php. Acesso em: 10 dez. 2017

RILEM. Recommendations MR1-21: testing methods of mortar and rendering. Réunion Internationale des Laboratories d'Essais et Recherches Sur les Matériaux et lês Construction, v. 1, n. 1, 1982.

RODRIGUES et al. Physical-chemical and mineralogical characterization of fine aggregates from construction and demolition waste recycling plants. Journal of Cleaner Production. v. 52, p. 438-445, 2013.

SAIZ MARTÍNEZ, P. et al. Comparative study of three types of fine recycled aggregates from construction and demolition waste (CDW), and their use in masonry mortar fabrication.Journal of Cleaner Production, v. 118, p. 162-169, 2016.

SAMPAIO, K. N. H. Avaliação técnica da utilização de cinzas de combustão do carvão mineral proveniente de termelétrica em argamassas de revestimento. Fortaleza, 2017. 102 f. Dissertação (Mestrado em Engenharia Civil) - Programa de Pós-Graduação em Engenharia Civil, Universidade Federal do Ceará, Fortaleza, 2017. 
SANTANA, T. S.; ARAÚJO, T. V; PEREIRA, C. H. F. Reaproveitamento de resíduos da construção civil produzidos no Distrito Federal para a produção de argamassa de revestimento. In: SIMPÓSIO BRASILEIRO DE TECNOLOGIA DAS ARGAMASSAS, 12., São Paulo, 2017. Anais [...]São Paulo, 2017.

SHEEN, Y.-N. et al. Assessment on the engineering properties of ready-mixed concrete using recycled aggregates. Construction and Building Materials, v. 45, p. 298-305, 2013.

SILVA, D. A. A. Estudo de viabilidade técnica de agregados reciclados de RCD na produção de contrapiso. Fortaleza, 2014. 62 f. Monografia (Graduação em Engenharia Civil) - Centro de Tecnologia, Universidade Federal do Ceará, Fortaleza, 2014.

SILVA, N. G. Argamassa de revestimento de cimento, cal e areia britada de rocha calcária. Curitiba, 2006. 176 f. Dissertação (Mestrado em Construção Civil) - Setor de Tecnologia,Universidade Federal do Paraná, Curitiba, 2006.

SILVA, N. G.; CAMPITELI, V. C. Correlação entre módulo de elasticidade dinâmico e resistências mecânicas de argamassas de cimento, cal e areia. Ambiente Construído, Porto Alegre, v. 8, n. 4, p. 21-35, out./dez. 2008.

SILVA, R. V.; BRITO, J.; DHIR, R. K. Performance of cementitious renderings and masonry mortars containing recycled aggregates from construction and demolition wastes. Construction and Building Materials, v. 105, p. 400-415, 2016

SILVA, R. V.; BRITO, J.; DHIR, R. K. Properties and composition of recycled aggregates from construction and demolition waste suitable for concrete production. Construction and Building Materials, v. 65 , p. 201-217, 2014.

STEFANIDOU, M.; ANASTASIOU, E.; GEORGIADIS FILIKAS, K. Recycled sand in lime-based mortars. Waste Management, v. 34, n. 12, p. 2595-2602, 2014.

ULSEN, C. et al.Composição química de agregados mistos de resíduos de construção e demolição do Estado de São Paulo. REM: Revista Escola de Minas, v. 63, n. 2, p. 339-346, 2010.

VIEIRA, G. L.; DAL MOLIN, D. C. C. Viabilidade técnica da utilização de concretos com agregados reciclados de resíduos de construção e demolição. Ambiente Construído, Porto Alegre, v. 4, n. 4, p. 47-63, out./dez. 2004.

VOTORANTIM CIMENTOS. Boletim de ensaios de cimento. Sobral, 2017.

YEHEYIS, M. et al. An overview of construction and demolition waste management in Canada: a lifecycle analysis approach to sustainability. Clean Technologies and Environmental Policy, v. 15, n. 1, p. 81-91, 2013.

YUAN, H. P. et al. A model for cost-benefit analysis of construction and demolition waste management throughout the waste chain. Resources, Conservation and Recycling, v. 55, n. 6, p. 604-612, 2011.

ZORDAN, S. E. A utilização do entulho como agregado, na confecção do concreto. Campinas, 1997. 156 f. Dissertação (Mestrado em Engenharia Civil) - Faculdade de Engenharia Civil, Universidade Estadual de Campinas, Campinas, 1997.

\section{Agradecimentos}

Os autores agradecem à Coordenação de Aperfeiçoamento de Pessoal de Nível Superior (Capes), pelo financiamento da pesquisa durante o mestrado no Programa de Pós-Graduação em Engenharia Civil: Estruturas e Construção Civil da Universidade Federal do Ceará, e ao Grupo de Pesquisa em Materiais de Construção e Estruturas(GPMATE), pela infraestrutura física necessária ao estudo. 


\section{Davi Valente Santos}

Gerência de Materiais, Departamento de Engenharia Civil, Núcleo de Tecnologia e Qualidade Industrial do Ceará | Faculdade Ari de Sá Rua Prof. Rômulo Proença, s/n | Fortaleza -CE - Brasil | CEP 60440-552 | Tel.: (85) 98861-9255 | E-mail: davivs@gmail.com

\section{Antonio Eduardo Bezerra Cabral}

Departamento de Engenharia Estrutural e Construção Civil | Universidade Federal do Ceará | Campus Universitário do Pici, Bloco 710 | Fortaleza -CE - Brasil | CEP 60455 | Tel.: (85) 3366-9607 | E-mail: eduardo.cabral@ufc.br

\section{Ambiente Construído}

Revista da Associação Nacional de Tecnologia do Ambiente Construído Av. Osvaldo Aranha, $99-3^{\circ}$ andar, Centro

Porto Alegre - RS - Brasil CEP 90035-190

Telefone: +55 (51) 3308-4084

Fax: +55 (51) 3308-4054

www.seer.ufrgs.br/ambienteconstruido

E-mail: ambienteconstruido@ufrgs.br

This is an open-access article distributed under the terms of the Creative Commons Attribution License. 